\title{
Antiproliferative activity of a series of 5-(1H-1,2,3-triazolyl) methyl- and 5-acetamidomethyl-oxazolidinone derivatives
}

\author{
OMAR M. HEDAYA, PRINCY M. MATHEW, FATIMA H. MOHAMED, \\ OLUDOTUN A. PHILLIPS and YUNUS A. LUQMANI
}

\author{
Department of Pharmaceutical Chemistry, Faculty of Pharmacy, Kuwait University, Safat 13110, Kuwait
}

Received May 26, 2015; Accepted February 2, 2016

DOI: $10.3892 / \mathrm{mmr} .2016 .4938$

\begin{abstract}
In the face of increasing resistance to the existing antibiotics, oxazolidinones (exemplified by linezolid) have been developed as promising antibacterial agents, but may have other useful actions. In the present study, a series of 5-(1H-1,2,3-triazoly) 1-methyl-, 5-acetamidomethyl-morpholino and $\mathrm{N}$-substituted-piperazino oxazolidinone derivatives were investigated to determine whether they are active against eukaryotic cells. An MTT assay, validated by cell counting, was used to assess the effect of nine oxazolidinone derivatives (concentrations $100 \mathrm{nM}-10 \mu \mathrm{M}$ ) on the proliferation of MCF7 human breast cancer cells. The three most active compounds were then tested on MDA231 breast cancer cells. Cytotoxicity of the selected derivatives was determined by assessing the extent of apoptosis by flow cytometry. The antimetastatic potential of these compounds was assessed on MDA231 cells using wound healing and agarose invasion assays. The 5-triazolylmethyl piperazino-oxazolidinone derivatives containing 4- $N$-(2-chlorocinnamoyl), 4- $N$-(4-nitrobenzoyl) and 4- $N$-methylsulfonyl moieties exhibited the most potent cytostatic activity against cancer, inhibiting proliferation by up to $70 \%$, in the same order as their reported antibacterial activity against Staphylococcus aureus, but at higher concentrations. Unexpectedly, several derivatives stimulated proliferation at $100 \mathrm{nM}$, well below their antibacterial minimum inhibitory concentrations. Certain compounds also retarded the motility and invasion of MDA231 cells. Three of the tested derivatives had no effect on the eukaryotic cell lines, demonstrating their preferential activity against bacteria. Two compounds actually stimulated eukaryotic cell proliferation. The remaining three exhibited potent cytostatic activity against and cancer cells, displaying differences in response at low and high concentrations, which may suggest
\end{abstract}

Correspondence to: Professor Yunus A. Luqmani, Department of Pharmaceutical Chemistry, Faculty of Pharmacy, HSC Building, Kuwait University, Jabriya, Block 4, Safat 13110, Kuwait

E-mail: yunus@hsc.edu.kw

Key words: oxazolidinones, cancer, metastasis, invasion, proliferation, antibacterials multiple targets on eukaryotic cells. These latter compounds may be useful as anticancer agents.

\section{Introduction}

Oxazolidinones are synthetic heterocyclic compounds demonstrating antimicrobial properties against resistant Gram-positive pathogenic bacteria and Mycobacterium tuberculosis. Furazolidone 1 (Fig. 1), a synthetic nitrofuran oxazolidinone was the first described member of this class of compounds with antimicrobial activity targeting bacterial DNA. However, several studies on other oxazolidinone derivatives have also presented data indicating diverse biological activities, such as anticancer, anticoagulant, antithyroid and central nervous system effects, as well as inhibition of monoamine oxidases (1-4). A recent study by Sun et al (5), reported that furazolidone induced $\mathrm{S}$ phase cell cycle arrest, suppressed cell growth, increased phosphorylated p38 (p-p38) activity and decreased the activity of phosphorylated c-Jun $\mathrm{N}$-terminal protein kinase in HepG2 human hepatoblastoma cells. Furthermore, another study (2) demonstrated antileukemic properties of furazolidone in acute myeloid leukemia cells in vitro, through increased stability of tumor suppressor p53 protein. Furazolidone has also been reported to induce genotoxicity and carcinogenicity in certain cell types (6). In addition, other oxazolidinone derivatives (Fig. 1), namely 2 (BAY a 5830) (7), the 2-nitro-1H-imidazol-1-yl oxazolidinone 3 (1), and chloroquinoline oxazolidinone 4 have been shown to exhibit anticancer properties (8). More recently, Naresh et al (9) reported the activity of cytoxazone-linezolid hybrid oxazolidinone derivatives exemplified by 5 (Fig. 1) against DU145 prostate and A549 lung cancer cell lines.

Linezolid 6 (Fig. 1) is a totally synthetic oxazolidinone with efficacy against Gram-positive bacteria, including multidrug-resistant strains, namely methicillin-resistant Staphylococcus aureus (MRSA), penicillin-resistant Streptococcus pneumoniae (PRSP) and vancomycin-resistant enteroccoci (VRE) $(10,11)$. Generally, oxazolidinones, including linezolid, inhibit bacterial ribosomal protein biosynthesis with virtually no effect on DNA and RNA synthesis $(12,13)$. Other studies $(14,15)$ have shown that this class of compounds bind to the 50S ribosomal subunit, in particular to the A-site. As a consequence, oxazolidinones have been suggested to possess the ability to bind mitochondrial ribosomes, leading to inhibition 


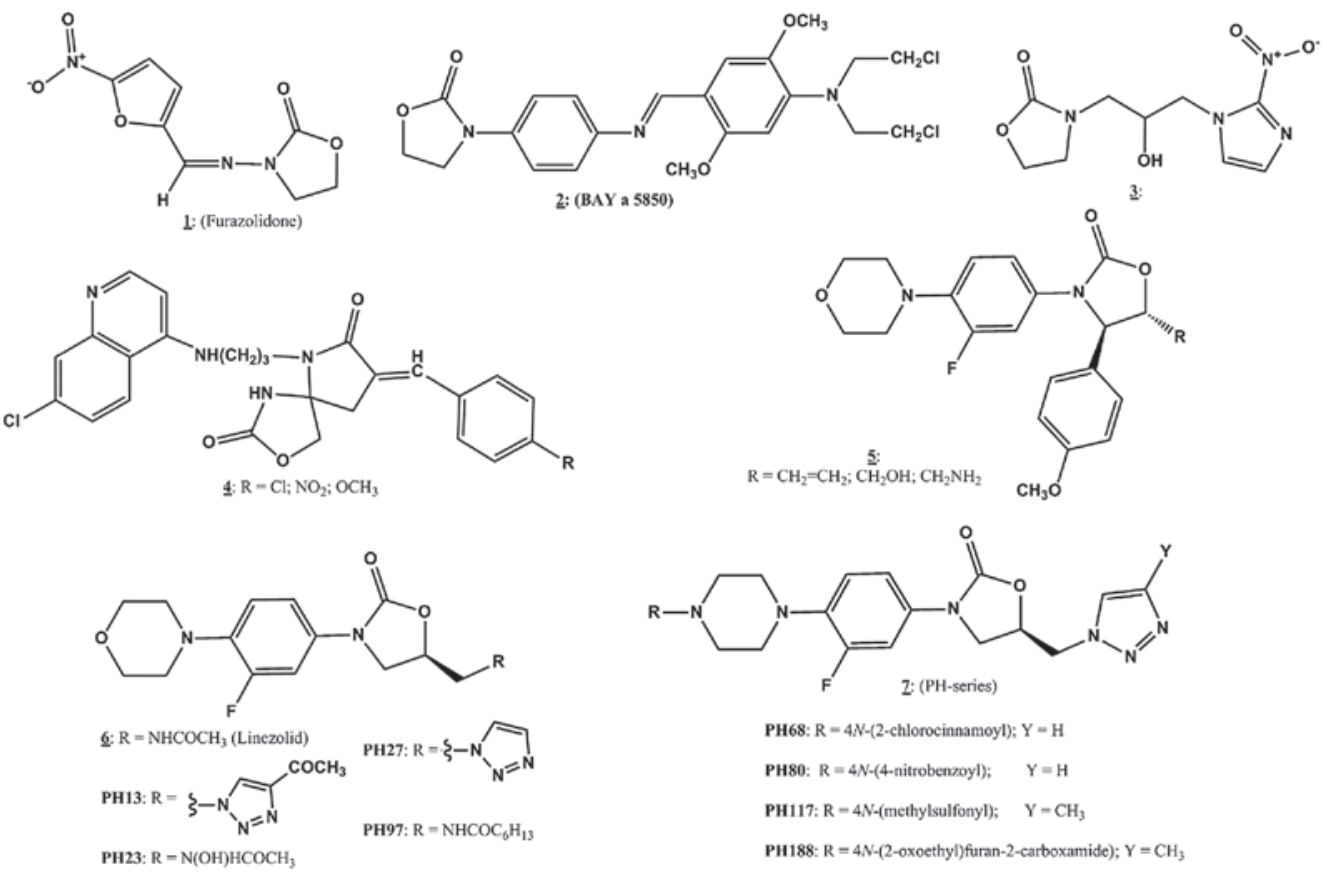

Figure 1. Chemical structures of biologically active oxazolidinone derivatives.

of mammalian mitochondrial protein synthesis, which could translate to drug toxicity in humans $(16,17)$. In addition, antibacterial agents of the oxazolidinone class also cause undesirable side effects, such as bone marrow suppression $(18,19)$, inhibition of monoamine oxidases (20), linezolid-induced neuropathy (21) and linezolid-associated toxic optic neuropathy (22) usually during prolonged courses of linezolid treatment. The mechanism of neuronal side effects has been suggested to be due to the impairment of mitochondrial protein synthesis. Furthermore, lactic acidosis and pancytopenia have also been reported in the clinic during linezolid treatment in a number of patients (23-25). Despite these effects, linezolid is deemed to be a clinically successful antibacterial drug for treating infections due to multi-drug resistant bacterial pathogens. Overcoming these challenges and other pharmacokinetic issues continues to be a focus of pharmaceutical scientists who are exploiting the oxazoldinone pharmacophore as a basic nucleus for further drug discovery and development for the treatment of human diseases.

In this regard, the present study and other studies (1,26-28) have evaluated several structural analogs of linezolid in search of newer derivatives with improved antibacterial activity. In view of the diverse biological activities exhibited by substituted oxazolidinone derivatives, the present study evaluated the effects of selected optionally substituted oxazolidinone derivatives, namely, the 5-heptanamidomethyl-(PH-97) and 5-(1H-1,2,3-triazolylmethyl) oxazolidinone derivatives 7 (Fig. 1) and linezolid 6 (10) on the growth of several cancerous human cell lines. This study aimed to determine their potential alternative use as anticancer agents, and the specificity of their antimicrobial activity.

\section{Materials and methods}

Chemicals. The chemical structures of the oxazolidinone derivatives utilized in this study are presented in (Fig. 1).
Linezolid and 8 previously reported oxazolidinone derivatives PH13, PH23, PH27, PH68, PH80, PH97, PH117 and PH188 were synthesized following published protocols (10,26-28). The compounds were purified and characterized using appropriate spectroscopic (NMR, IR MS) and analytical (CHN analysis) methods. The purified compounds were dissolved in dimethyl sulfoxide (DMSO) and stored at $-20^{\circ} \mathrm{C}$ until use (within two weeks). 3-(4,5-dimethylthiazol-2-yl)-2,5-diphenyltetrazolium bromide (MTT) reagent was obtained from Promega Corporation (Madison, WI, USA). The phycoerythrin (PE) Annexin $\mathrm{V}$ apoptosis detection kit I was purchased from BD Biosciences (Franklin Lakes, NJ, USA).

Cell culture. MCF7 [estrogen receptor (ER) ${ }^{+}$] and MDA231 $\left(\mathrm{ER}^{-}\right)$human breast cancer cell lines were derived from the American Type Culture Collection (Manassas, VA, USA) and routinely maintained at $37^{\circ} \mathrm{C}$ in a humidified atmosphere of $5 \% \mathrm{CO}_{2}$ in Dulbecco's modified Eagle's medium (DMEM) supplemented with $10 \%$ fetal bovine serum (FBS), $600 \mathrm{mg} / \mathrm{ml}$ L-glutamine, $100 \mathrm{U} / \mathrm{ml}$ penicillin- $100 \mathrm{mg} / \mathrm{ml}$ streptomycin and $6 \mathrm{ml}$ 100x non-essential amino acids $/ 500 \mathrm{ml}$ (all purchased from Invitrogen; Thermo Fisher Scientific, Inc., Waltham, MA, USA).

Cell motility assay. Cells were grown to $\sim 90 \%$ confluency in 24-well plates. Guided by a ruler, a fine scratch was made with a yellow Eppendorf pipette tip through the center of the monolayer. Detached cells were removed by gentle washing with phosphate-buffered saline and fresh medium was added. The width of the scratch was recorded from photographs taken under phase-contrast light microscopy (DM IL LED; Leica Microsystems Gmbh, Wetzlar, Germany) by an attached camera (Leica DFC500; Leica Microsystems GmbH) immediately, and after $24 \mathrm{~h}$, to determine the extent of migration of cells to re-fill the space. 
Table I. MIC values of oxazolidinone derivatives.

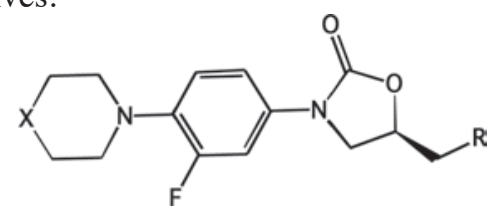

MIC $S$. aureus

\section{Code}

Linezolid

PH13

PH23

PH27

PH68<smiles>NC(=O)/C=C/c1ccccc1Cl</smiles>

PH80

PH97

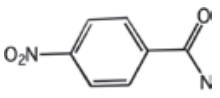

$\mathrm{O}$

PH117<smiles>CS(N)(=O)=O</smiles>

PH188

X

$\mathrm{O}$

$\mathrm{O}$<smiles>CC(=O)c1cn(I)nn1</smiles><smiles>CCN(O)C(C)=O</smiles><smiles>Cn1ccnn1</smiles><smiles>In1ccnn1</smiles><smiles>In1ccnn1</smiles><smiles>CCCCCCC(=O)NC</smiles><smiles>Cc1cn(I)nn1</smiles><smiles>Cc1cn(I)nn1</smiles>

nd

8

1

$>32$

MIC, minimum inhibitory concentration ( $\mu \mathrm{g} / \mathrm{ml}$ ) against Staphylococcus aureus (26-28). nd, not determined.

Agarose invasion assay. After melting in PBS, ultra-pure agarose (Invitrogen, Thermo Fisher Scientific Inc.) was supplemented with DMEM with 5\% FBS to give a final $0.5 \%$ solution, and allowed to solidify in individual wells of 6-well dishes at room temperature. Once set, 1-3 sample chambers (3.5 $\mathrm{mm}$ in diameter) were created in the gel, $2.5 \mathrm{~mm}$ apart in a horizontal line, by insertion of a metallic mold made for the present study. Cells $\left(4 \times 10^{4}\right)$ were re-suspended in complete DMEM and loaded into formed chambers. Plates were incubated at $37^{\circ} \mathrm{C}$ in a $5 \% \mathrm{CO}_{2}$ humidified atmosphere. After $24 \mathrm{~h}$, cells that had penetrated the agarose were manually counted by visual microscopic examination (DM IL LED). Random cell invasion was determined as the total number of cells that moved in both lateral directions out of the well into the surrounding agarose (29).

Cell proliferation assay. Approximately $200 \mu 1 \mathrm{MCF} 7$ or MDA231 cells re-suspended in DMEM at $5 \times 10^{3}$ cells $/ \mathrm{ml}$ were seeded in quadruplicates into 96 -well plates and allowed to attach overnight. Either vehicle only (DMSO) or oxazolidinone 

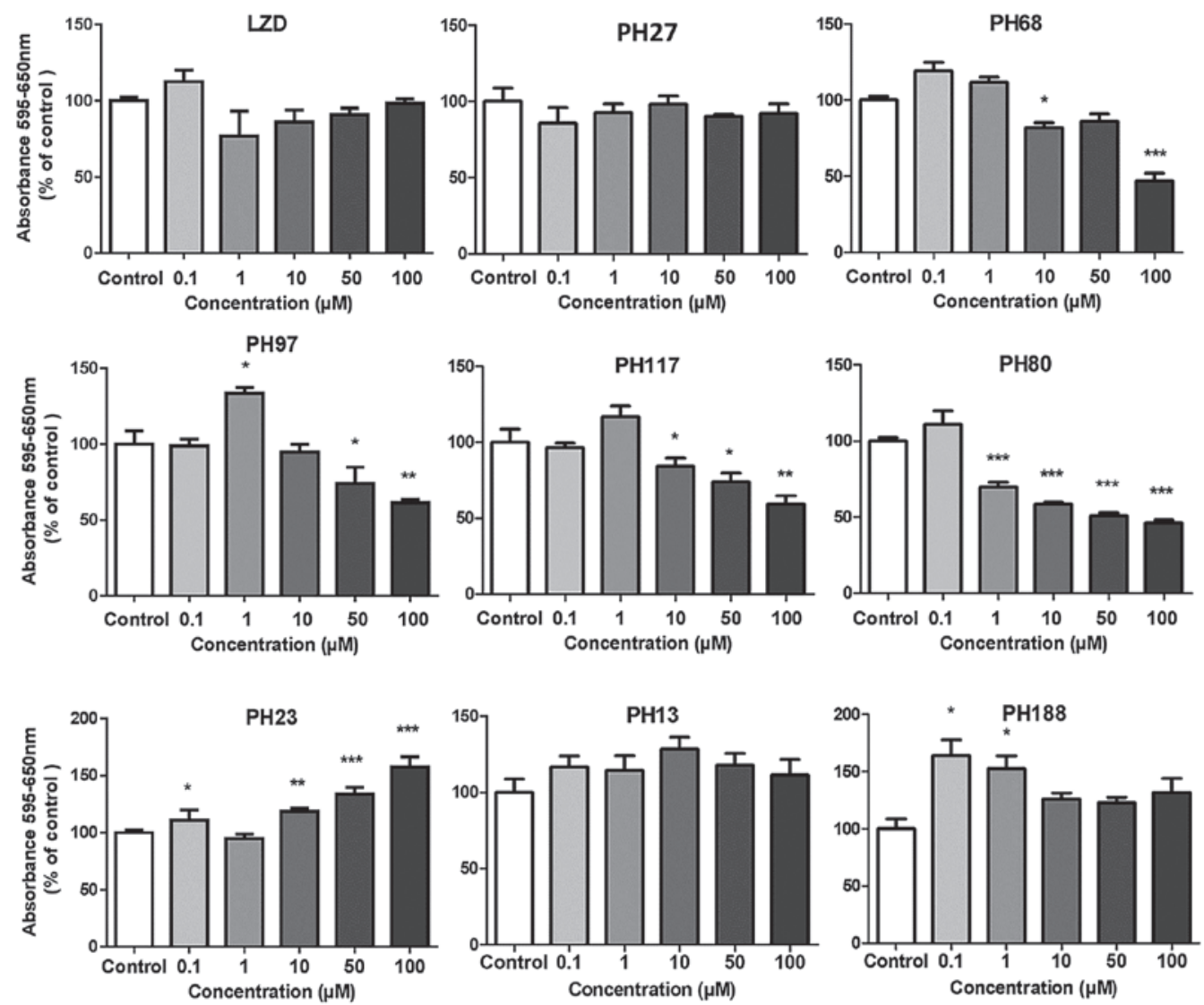

Figure 2. Effect of oxazolidinone derivatives on the growth of MCF7 cells assessed by an 3-(4,5-dimethylthiazol-2-yl)-2,5-diphenyltetrazolium bromide assay after 4 days of exposure. Control values (exposure to vehicle only) were arbitrarily set at $100 \%$ and drug conditions (concentrations as indicated) expressed as a $\%$ of this value. ${ }^{*} \mathrm{P}<0.05,{ }^{* *} \mathrm{P}<0.01$ and ${ }^{* * *} \mathrm{P}<0.001$, compared with control.

compounds $(100 \mathrm{nM}-10 \mu \mathrm{M})$ were then added to the cells. Growth was assessed by an MTT assay after 4 days of incubation. Briefly, $100 \mu \mathrm{l}$ MTT $(0.5 \mathrm{mg} / \mathrm{ml})$ was added to each well and plates incubated at $37^{\circ} \mathrm{C}$ for 30 min followed by the addition of $100 \mu \mathrm{l}$ of acidified isopropanol (Sigma-Aldrich) and vigorous re-suspension of the converted blue dye crystals. Absorbance of the suspension was measured at $595 \mathrm{~nm}$ using a Thermo Scientific Multiskan Spectrum plate reader (Thermo Fisher Scientific, Inc.) with background subtraction at $650 \mathrm{~nm}$. The effect of the compounds was compared with the untreated control cells (taken as 100\%). Each experiment was repeated a minimum of three times (with quadruplicates) with different batches of cells.

Flow cytometry. MCF7 cells were incubated in 6-well plates with PH80, $\mathrm{PH} 68$ and $\mathrm{PH} 117$ at $100 \mu \mathrm{M}$ in triplicate for 3 days. Cell monolayers were trypsinized (Invitrogen; Thermo Fisher Scientific, Inc.), pelleted by centrifugation at $1,000 \mathrm{x} \mathrm{g}$ for 3 min and washed twice by re-suspension and centrifugation in ice-cold PBS at $1,000 \mathrm{xg}$ at $3^{\circ} \mathrm{C}$ and once in Annexin- $\mathrm{V}$ binding buffer (10 mM HEPES/NaOH, pH 7.4; $0.14 \mathrm{M} \mathrm{NaCl}$; and $2.5 \mathrm{mM} \mathrm{CaCl}_{2}$ ). The final cell pellet was re-suspended in $100 \mu \mathrm{l}$ of Annexin-V binding buffer at $5 \times 10^{6} \mathrm{cell} / \mathrm{s} / \mathrm{ml}$ and processed for FACS analysis on an FC500 flow cytometer (Beckman Coulter, Inc., Brea, CA, USA) using the phycoerythrin (PE) Annexin V apoptosis detection kit I. Cells were stained in the following manner: (A), cells only (negative control); (B), with $10 \mu 1$ Annexin V-PE; (C), with $20 \mu 1$ 7AAD; and (D), with $10 \mu 1$ Annexin V-PE plus $20 \mu 1$ 7AAD. All incubations were performed in the dark at room temperature for $15 \mathrm{~min}$.

Statistical analysis. Differences between the mean values of control compared with treated groups were analyzed by Student's t-test and one-way analysis of variance for multiple comparisons (different doses of the therapeutic agents) using GraphPad Prism 5 (GraphPad Software, Inc., La Jolla, CA, USA). $\mathrm{P}<0.05$ was considered to indicate a statistically significant difference.

\section{Results}

Effect of oxazolidinone derivatives on the proliferation of MCF 7 breast cancer cells. The effects of linezolid and 8 oxazolidinone derivatives on the growth of MCF7 cells are shown in (Fig. 2). Linezolid and PH27 which have potent MIC values against bacteria (Table I) and PH13, which does not, showed no significant inhibition at any concentration, indicating that neither the 5-acetamido nor the 5-triazolyl substitution on the morpholino derivatives resulted in any observable antiproliferative effect. Conversely, the oxazolidinone derivatives containing piperazino-5-(1H-1,2,3-triazolyl) methyl (PH68, PH80 and PH117) and the morpholino-5-heptanoyl) methyl (PH97) groups, which have potent antibacterial activity, showed significant dose-dependent activity towards MCF7 cells. At $100 \mu \mathrm{M}$ they caused 50-60\% inhibition of 

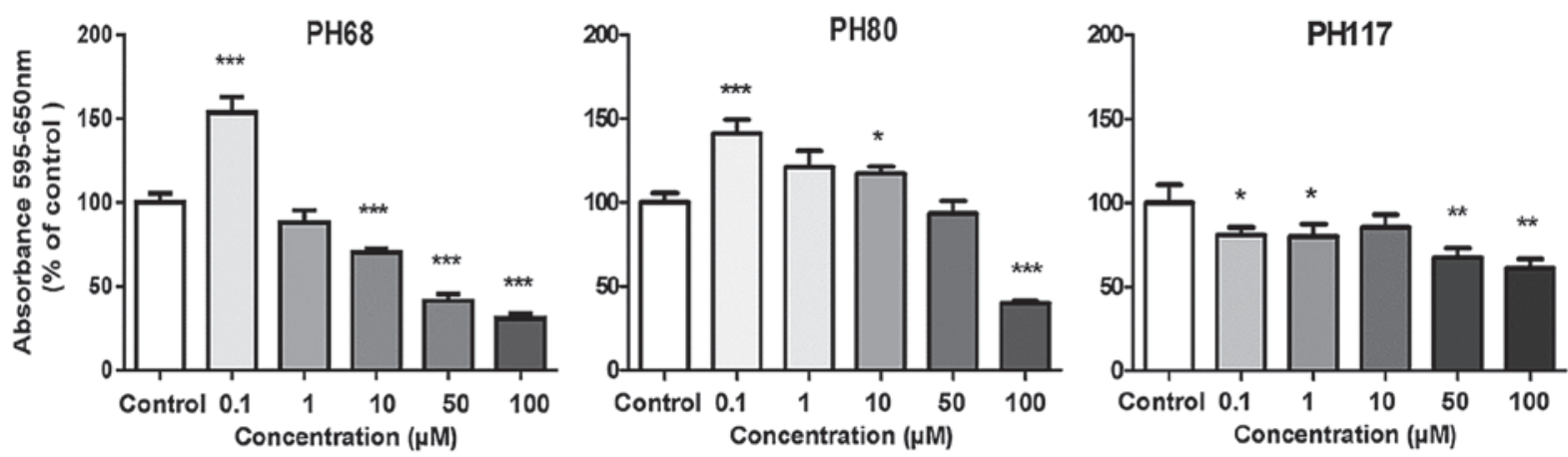

Figure 3. Effect of oxazolidinone derivatives PH68, PH80 and PH117 on the growth of MDA231 cells assessed by an MTT assay after 4 days of exposure. Controls (exposure to vehicle only) were arbitrarily set at $100 \%$ and drug conditions (concentrations as indicated) expressed as a $\%$ of this value. ${ }^{*} \mathrm{P}<0.05$, ${ }^{* *} \mathrm{P}<0.01$ and ${ }^{* * *} \mathrm{P}<0.001$, compared with control.

cell proliferation. However, the morpholino-(5-heptanoyl) methyl derivative, PH97, exhibited a biphasic effect, causing growth stimulation at $1 \mu \mathrm{M}$ and inhibition at 50-100 $\mu \mathrm{M}$. The piperazino-5-hydroxamic acid derivative, $\mathrm{PH} 23$, which has poor antibacterial activity actually stimulated growth significantly at 10-100 $\mu \mathrm{M}$. The $N$-(furan-2-carboxamide) glycinyl piperazinyl-5- (1H-1,2,3-triazol-1-yl)methyl) oxazolidinone derivative, PH188, also stimulated growth but only significantly at the lower concentrations of $10 \mathrm{nM}-1 \mu \mathrm{M}$.

Effect of PH68, PH80 and PH117 on proliferation of breast cancer cells. Based on the initial observations with MCF7 cells, the piperazino-5 (1H-1,2,3-triazolyl) methyl derivatives containing $N$-(2-chlorocinnamoyl) (PH68), $N$-(4-nitrobenzoyl) (PH80) and $N$-(methylsulfonyl) (PH117) groups were selected for further assessment. These were tested for their effect on the growth of a more aggressive breast cancer cell line, MDA231. The results (Fig. 3) were similar for the two cell lines and consistent with their previously observed effect on MCF7 cells. The most potent compound was the $N$-piperazinyl-(2-chlorocinnamoyl) derivative PH68 with marked inhibition from $10 \mu \mathrm{M}$ and reaching $80 \%$ inhibition at $100 \mu \mathrm{M}$, with the others being less effective (Fig. 3). PH117 exhibited $\sim 50 \%$ inhibition from $50 \mu \mathrm{M}$ and PH80 at $100 \mu \mathrm{M}$. However, all the three compounds showed pronounced (150\%) stimulation of growth at lower concentrations of $100 \mathrm{nM}$. The same phenomenon was observed in MCF7 cells but the magnitude of the effect was insufficient to be of statistical significance.

Assessment of cytotoxicity. Flow cytometry was used to determine the extent of apoptosis induced by PH68, PH80 and PH117 (Fig. 4). Neither PH68 nor PH117 affected the viability of MCF7 cells, whilst PH80 induced a significant reduction of the viable population of cells by $36 \%$, and a $69 \%$ increase in apoptosis.

Cell motility. The wound closure assay (30) was used to determine the effects of PH68, PH117 and PH80 on the motility of MDA231 cells. At concentrations of 50 and $100 \mu \mathrm{M}$, PH68 and PH80 inhibited wound closure by 50\% as compared with cells treated with vehicle alone (DMSO). Conversely, at a concentration of $100 \mathrm{nM}$, they actually stimulated cell motility

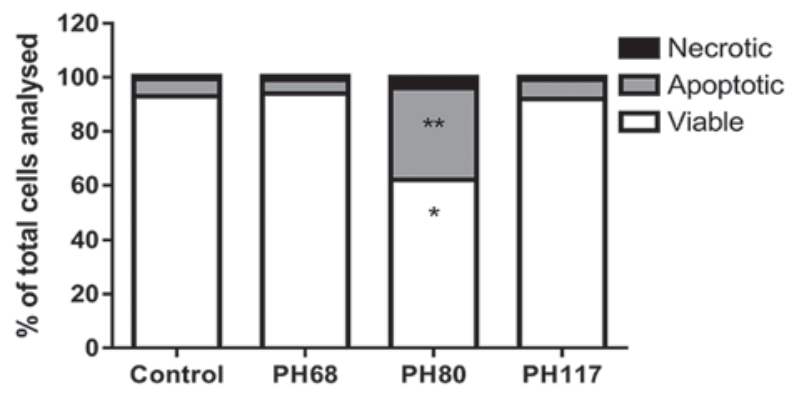

Figure 4. Flow cytometric analysis. MCF7 cells were plated in triplicate in 6 -well plates and exposed to either vehicle or drug as indicated for $24 \mathrm{~h}$ and processed for flow cytometry using the phycoerythin-Annexin $\mathrm{V}$ apoptosis detection kit I. Histobars show proportion of viable, apoptotic and necrotic cells in comparison to control set at $100 \%$. ${ }^{*} \mathrm{P}<0.05$ and ${ }^{* *} \mathrm{P}<0.01$, compared with control.

and closed the wound to a significantly greater extent than observed for control vehicle treated cells (Fig. 5). In the case of cells treated with PH117 at either a low or high dose, there was no significant difference from vehicle treatment.

Cell invasion assay. The invasion assay described previously (29) was used to determine the effect of PH68, PH80 and PH117 on the ability of MDA231 cells to penetrate agarose gel. As shown in (Fig. 6), at high doses (PH68 $50 \mu \mathrm{M}$; PH117 $50 \mu \mathrm{M}$; PH80 $100 \mu \mathrm{M}$ ) all three drugs produced significant inhibition of invasion by $50 \%$. At low doses (100 nM), only PH68 exhibited significant inhibition of invasion.

\section{Discussion}

Antibiotics active solely against prokaryotic organisms have become indispensable to human health. Moreover, onset of bacterial resistance to these drugs continues to pose a serious threat that has led to extensive efforts to overcome this by developing novel potent agents. Linezolid is an antibiotic that belongs to the oxazolidinone class of compounds, which are often the last resort when other antibiotic therapies have failed. The great success of antibiotics has been due to the fact that their mode of action specifically targets the characteristics that distinguish prokaryotic from eukaryotic mechanisms, preventing unwanted side effects. It is important that novel 
A

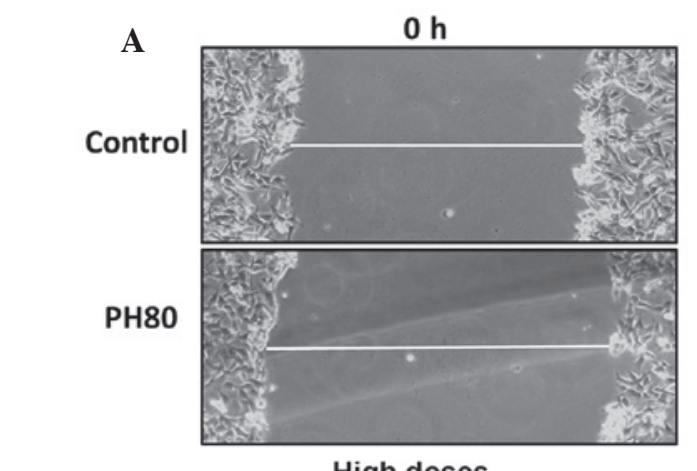

B

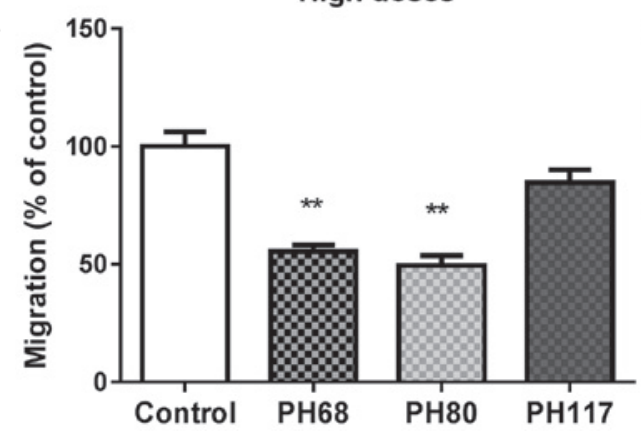

$24 \mathrm{~h}$

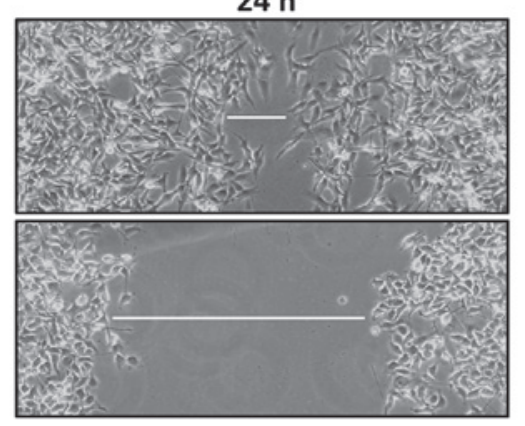

$100 \mathrm{nM}$

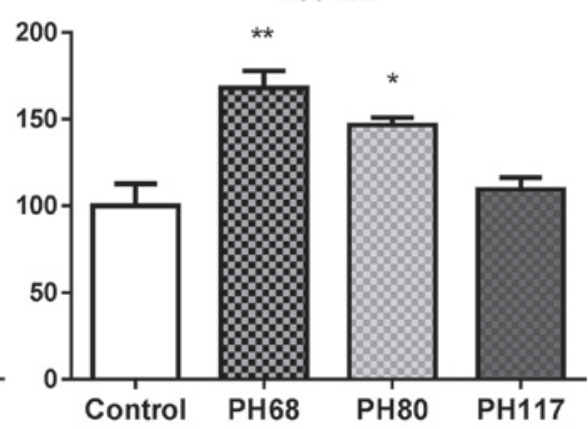

Figure 5. Cell motility assay. MDA231 cells were plated in 6-well dishes and grown to 90\% confluency. A central scratch was made and the width of the created gap measured immediately, as well as after $24 \mathrm{~h}$ incubation. The upper panel (A) illustrates a typical result where the gap is only partially closed by movement of cells exposed to PH80 vs. control. The histograms in Panel B (means \pm standard error of the mean of at least 6 independent determinations) show the effect of high (PH68 at $50 \mu \mathrm{M} ; \mathrm{PH} 80$ at $100 \mu \mathrm{M}$; PH117 at $50 \mu \mathrm{M})$ and low doses $(100 \mathrm{nM})$ of PH68, PH80, and PH117 on cell mobility. ${ }^{*} \mathrm{P}<0.05$ and *** $\mathrm{P}<0.01$, compared with control.

A

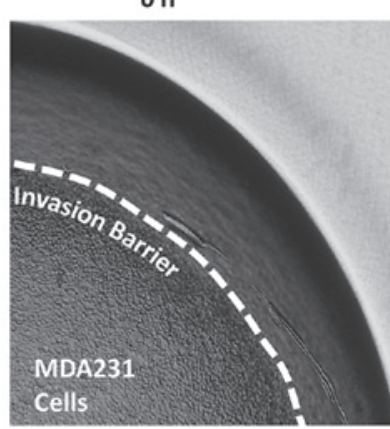

$24 \mathrm{~h}$ (untreated)

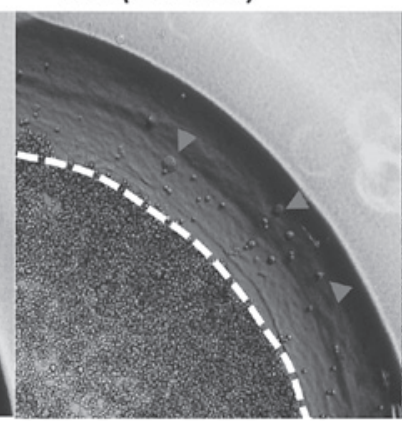

24 h (+PH68)

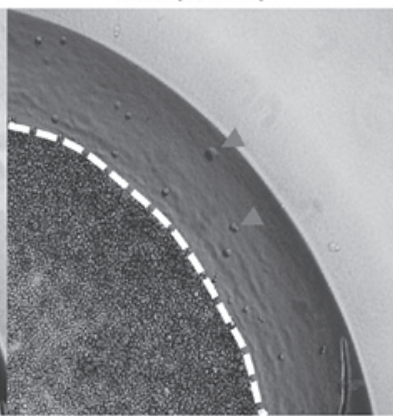

B

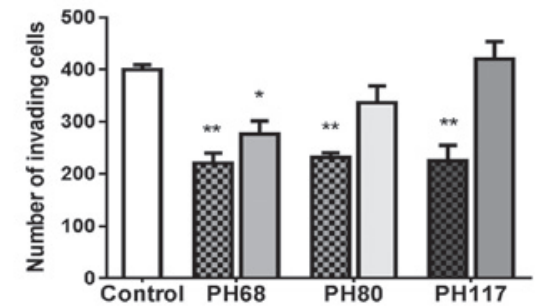

Figure 6. In the cell invasion assay, MDA231 cells were added to chambers created in a layer of agarose in 6-well dishes and the number of cells moving into the agarose were counted after $24 \mathrm{~h}$ incubation. Upper panel (A) illustrates a microscopic view of the well at the start and after $24 \mathrm{~h}$ in the presence of PH68 or vehicle only; fewer penetrating cells being seen in the former case. (B) Histogram presented as the mean \pm standard error of the mean of at least 4 such independent determinations, made in the presence of high (hatched bars) and low (plain bars) doses of PH68, PH80 and PH117. ${ }^{*} \mathrm{P}<0.05$ and ${ }^{* *} \mathrm{P}<0.01$, compared with control.

agents do not exhibit any effects on eukaryotic cells. Certain oxazolidinones have been shown not only to exhibit antimicrobial properties but also to affect human cells. It is therefore essential to distinguish these agents to prevent potential adverse effects. At the same time, their dual action could be put to good use. Several studies (1-4) have suggested that application of oxazolidinones may provide significant therapeutic benefits in cases of HIV, cancer and epilepsy. In this study, linezolid and eight other oxazolidinone derivatives bearing 5-hydroxamate-, 5-heptanoyl- and 5-(1H-1,2,3-triazolyl)-methyl moieties were initially screened for possible inhibitory effects on eukaryotic cells. The $\mathrm{ER}^{+} \mathrm{MCF} 7$ breast cancer line is well studied, and 
is an example of a commonly used eukaryotic cell line, for the initial evaluation. Significant differences were observed between these compounds which had no direct correlation with their antibacterial activity. The prototype compound linezolid, and its 5-(1H-1,2,3-triazolyl) methyl derivatives PH27 and PH13 had no significant effect on MCF7 cell proliferation and were not investigated further. These are considered to be safe antibacterial agents. Mixed effects were observed with the remaining 6 compounds. The compounds $\mathrm{PH} 23$ and PH188 appear to be unsuitable as anti-microbial agents given their MIC values (>95 and 24 respectively) in a range where they actually stimulate eukaryotic cell growth. This would be particularly problematic if administered to cancer patients. The precise mechanism for the stimulation is not clear at this time. By contrast, PH68, PH117 and PH80 all exhibited dose-dependent inhibition of MCF7, MDA231 and HBL100 proliferation, which may equally compromise their anti-bacterial use. However, in another context, these compounds may be of use as anticancer agents instead. Notably, however, they display the phenomenon of 'hormesis', a term widely used by toxicologists to describe a biphasic dose response to a drug, with stimulatory effects at low dose and inhibition at higher doses; thought to be an adaptive compensatory response to initial disruption of cellular homeostasis $(31,32)$. At low doses a drug could block an endogenous inhibitory factor, resulting in stimulation, before it starts to exert its own inhibitory effect on other pathways at higher concentration. Furthermore, to distinguish between their cytostatic and potential cytotoxic activity, MCF7 cells treated with these 3 compounds were analyzed for evidence of apoptosis by flow cytometry using Annexin/7-AAD labeling. The results indicated that only the $\mathrm{N}$-piperazino-4-nitrobenzoyl-5 (1H-1,2,3-triazolyl) methyl derivative PH80 induced cell death. It is notable that this compound has a terminal nitro-group, which may be responsible for the cytotoxicity. Nitro groups attached to aromatic rings may be metabolically converted to potentially lethal reactive intermediates. This type of conversion (by the $\mathrm{P} 450$ enzymes) has been reported for the nitro-imidazole group in the antibiotic nitrofurantoin, and has been suggested to be responsible for its anticancer effects (33).

Much of the difficulty in the treatment of solid cancers is in the control of disseminated disease, and thus preventing its spread would greatly enhance treatment. In this regard, the ability of these drugs to block tumor cell motility and invasion was determined. Of the three compounds that effectively reduced proliferation, only PH68 and PH80 (at 50 and $100 \mu \mathrm{M}$, respectively) significantly retarded cell movement. Notably, at a lower dose of $100 \mathrm{nM}$, PH68 and PH80 actually stimulated cell migration, paralleling the phenomenon observed with proliferation (although in that case it was not identified to be significant). With respect to invasion of MDA231 cells, all three compounds had an inhibitory effect at the higher doses, with only PH68 also exhibiting the same effect at the lower dose. As these are complex processes involving multiple pathways, it is quite likely that the oxazolidinone derivatives may have selective as well as common cellular targets, accounting for the differences. Further studies are on-going in our laboratories on these compounds.

The observations suggest that linezolid, PH13, PH23 and PH27 lack anticancer activity against breast cancer cell lines and are suitable as antibacterial agents from that perspective. However, the triazolyl derivatives PH68, PH80 and PH117 exhibit activity against breast cancer cells and also inhibited cancer cell motility and invasion. Therefore these three compounds merit further investigation as potential anticancer agents particular as they affect several stages of cancer progression. Due to the limited number of compounds investigated in this study it was not possible to establish a meaningful structure-activity relationship for this class of compounds.

\section{Acknowledgements}

This study was supported by the Research Administration, Kuwait University Research Grant SRUL/0230 (Research Core Facility, Health Science Centers).

\section{References}

1. Pandit N, Singla RK and Shrivastava B: Current updates on oxazolidinone and its significance. Int J Med Chem 2012: 159285, 2012.

2. Jiang X, Sun L, Qui JJ, Sun X, Li S, Wang X, So CW and Dong S: A novel application of furazolidone: Anti-luekemic activity in acute myeloid leukemia. PLOS ONE 8: e72335, 2013.

3. Reck F, Zhou F, Girardot M, Kern G, Eyermann CJ, Hales NJ, Ramsay RR and Gravestock MB: Identification of 4-substituted 1,2,3-triazoles as novel oxazolidinone antibacterial agents with reduced activity against monoamine oxidase A. J Med Chem 48: 499-506, 2005.

4. Kombian SB and Phillips OA: In vitro electrophysiological investigations of the acute effects of linezolid and novel oxazolidinones on central nervous system neurons. Neurosci 180: 53-63, 2011.

5. Sun Y, Tang S, Jin X, Zhang C, Zhao W and Xiao X: Opposite effects of JNK and p38 MAPK signaling pathways on furazolidinone-stimulated $S$ phase cell cycle arrest of human hepatoblastoma cell line. Mutat Res 775: 24-29, 2013.

6. Auro A, Sumano H, Ocampo L and Barragán A: Evaluation of the carcinogenic effects of furazolidone and its metabolites in two fish species. The Pharmacogenomics J 4: 24-28, 2004.

7. Artico M, De Martino G and Giuliano R: Research on compounds with antiblastic activity. XL. Synthesis of 3-p-(2', 5'-dimethoxy-4'-(N, N-bis-(-chloroethyl)-amino)benzylideneamino) phenyl-2-oxazolidinone (GEA 29; BAY a 5850) and its analogues. Farmaco Sci 26: 771-783, 1971.

8. Devi K, Asmat Y, Agrawal M, Sharma S and Dwived J: Synthesis and evaluation of some novel precursors of oxazolidinone analogues of chloroquinoline for their antimicrobial and cytotoxic potential. J Chem Sci 125: 1093-1101, 2013.

9. Naresh A, Venkateswara Rao MV, Kotapalli SS, Ummanni R and Venkateswara Rao B: Oxazolidinone derivatives: Cytoxazone-linezolid hybrids induces apoptosis and senescence in DU145 prostate cancer cell. Eur J Med Chem 80: 295-307, 2014.

10. Brickner SJ, Hutchinson DK, Barbachyn MR, Manninen PR, Ulanowicz DA, Garmon SA, Grega KC, Hendges SK, Toops DS, Ford CW and Zurenko GE: Synthesis and antibacterial activity of U-100592 and U-100766, two oxazolidinone antibacterial agents for the potential treatment of multidrug-resistant gram-positive bacterial infections. J Med Chem 39: 673-679, 1996.

11. Wilcox MH: Update on linezolid: The first oxazolidinone antibiotic. Expert Opin Pharmacother 6: 2315-2326, 2005.

12. Eustice DC, Feldman PA, Zajac I and Slee AM: Mechanism of action of DuP 721: Inhibition of an early event during initiation of protein synthesis. Antimicrob Agents Chemother 32: 1218-1222, 1988.

13. Kalia V, Miglani R, Purnapatre KP, Mathur T, Singhal S, Khan S, Voleti SR, Upadhyay DJ, Saini KS, Rattan A and Raj VS: Mode of action of Ranbezolid against staphylococci and structural modeling studies of its interaction with ribosomes. Antimicrob Agents Chemother 53: 1427-1433, 2009. 
14. Zhou CC, Swaney SM, Shinabarger DL and Stockman BJ: 1H nuclear magnetic resonance study of oxazolidinone binding to bacterial ribosomes. Antimicrob Agents Chemother 46: 625-629, 2002.

15. Ippolito JA, Kanyo ZF, Wang D, Franceschi FJ, Moore PB, Steitz TA and Duffy EM: Crystal structure of the oxazolidinone antibiotic linezolid bound to the $50 \mathrm{~S}$ ribosomal subunit. J Med Chem 51: 3353-3356, 2008.

16. McKee EE, Ferguson M, Bentley AT and Marks TA: Inhibition of mammalian mitochondrial protein synthesis by oxazolidinones. Antimicrob Agents Chemother 50: 2042-2049, 2006.

17. De Vriese AS, Coster RV, Smet J, Seneca S, Lovering A, Van Haute LL, Vanopdenbosch LJ, Martin JJ, Groote CC, Vandecasteele S and Boelaert JR: Linezolid-Induced Inhibition of Mitochondrial Protein Synthesis. Clin Infect Dis 42: 1111-1117, 2006.

18. Kuter DJ and Tillotson GS: Hematologic effects of antimicrobials: Focus on the oxazolidinone linezolid. Pharmacotherapy 21 1010-1013, 2001

19. Gerson SL, Kaplan SL, Bruss JB, Le V, Arellano FM, Hafkin B and Kuter DJ: Hematologic effects of linezolid: Summary of clinical experience. Antimicrob Agents Chemother 46 : 2723-2726, 2002.

20. Leach KL, Brickner SJ, Noe MC and Miller PF: Linezolid, the first oxazolidinone antibacterial agent. Ann N Y Acad Sci 1222 49-54, 2011.

21. Corallo CE and Paull AE: Linezolid-induced neuropathy. Med J Aust 177: 332, 2002

22. Rucker JC, Hamilton SR, Bardenstein D, Isada CM and Lee MS Linezolid-associated toxic optic neuropathy. Neurology 66 : 595-598, 2006

23. Kraleti S and Soultanova I: Pancytopenia and lactic acidosis associated with linezolid use in a patient with empyema. J Ark Med Soc 110: 62-63, 2013.
24. Narita M, Tsuji BT and Yu VL: Linezolid-associated peripheral and optic neuropathy, lactic acidosis and serotonin syndrome. Pharmacotherapy 27: 1189-1197, 2007.

25. Su E, Crowley K, Carcillo JA and Michaels MG: Linezolid and lactic acidosis: A role for lactate monitoring with long-term linezolid use in children. Pediatr Infect Dis J 30: 804-806, 2011.

26. Phillips OA, Udo EE, Ali AA and Al-Hassawi N: Synthesis and antibacterial activity of 5-substituted oxazolidinones. Bioorg Med Chem 11: 35-41, 2003.

27. Phillips OA, Udo EE, Ali AAM and Samuel SM: Structure-antibacterial activity of arylcarbonyl- and arylsulfonyl-piperazine 5-triazolylmethyl oxazolidinones. Eur J Med Chem 42: 214-225, 2007.

28. Phillips OA, Udo EE, Abdel-Hamid ME and Varghese R: Synthesis and antibacterial activities of N-substituted-gylcinyl 1H-1,2,3-triazolyl oxazolidinones. Eur J Med Chem 66: 246-257, 2013.

29. Khajah MA, Al Saleh S, Mathew PM and Luqmani YA Differential Effect of Growth Factors on Invasion and Proliferation of endocrine resistant breast cancer cells. PLoS One 7: e41847, 2012

30. Liang C, Park A and Guan J: In vitro scratch assay: A convenient and inexpensive method for analysis of cell migration in vitro. Nat Protoco 2: 329-333, 2007.

31. Calabrese EJ and Blain R: The occurrence of hormetic dose responses in the toxicological literature, the hormesis database: An overview. Toxicol Appl Pharmacol 202: 289-301, 2005.

32. Nascarella M, Stanek E, Hoffmann GR and Calabrese EJ: Quantification of hormesis in anticancer-agent dose-responses. Dose-Response 72: 160-171, 2009.

33. Wang Y, Gray JP, Mishin V, Heck DE, Laskin DL and Laskin JD: Role of cytochrome $\mathrm{P} 450$ reductase in nitrofurantoin-induced redox cycling and cytotoxicity. Free Radical Bio Med 44: $1169-1179,2008$ 